\title{
ADELINE LATIMIER-IONOFF, Lire le nom propre dans le roman médiéval
}

\section{Graziella Pastore}

\section{(2) OpenEdition}

\section{Journals}

\section{Édition électronique}

URL : https://journals.openedition.org/studifrancesi/44595

DOI : 10.4000/studifrancesi.44595

ISSN : 2427-5856

\section{Éditeur}

Rosenberg \& Sellier

\section{Édition imprimée}

Date de publication : 1 août 2021

Pagination : 344

ISSN : 0039-2944

\section{Référence électronique}

Graziella Pastore, « ADELINE LATIMIER-IONOFF, Lire le nom propre dans le roman médiéval », Studi Francesi [En ligne], 194 (LXV | II) | 2021, mis en ligne le 06 septembre 2021, consulté le 15 octobre 2022. URL : http://journals.openedition.org/studifrancesi/44595; DOI : https://doi.org/10.4000/studifrancesi. 44595

Ce document a été généré automatiquement le 15 octobre 2022.

\section{(c)}

Creative Commons - Attribution - Pas d'Utilisation Commerciale - Pas de Modification 4.0 International - CC BY-NC-ND 4.0

https://creativecommons.org/licenses/by-nc-nd/4.0/ 


\title{
ADELINE LATIMIER-IONOFF, Lire le nom propre dans le roman médiéval
}

\author{
Graziella Pastore
}

\section{RÉFÉRENCE}

ADELINE LATIMIER-IONOFF, Lire le nom propre dans le roman médiéval, Paris, Classiques

Garnier, 2019, «Recherches littéraires médiévales» 28, 518 pp.

1 Issu d'une thèse de doctorat soutenue à l'Université Rennes 2 en décembre 2016, ce volume constitue une contribution importante dans le domaine des études sur le nom propre dans le roman médiéval et notamment dans la tradition arthurienne. L'ouvrage s'appuie sur cinq romans en vers des XIII ${ }^{\mathrm{e}}$ et XIV ${ }^{\mathrm{e}}$ siècles: Les Merveilles de Rigomer, Cristal et Clarie, Floriant et Florete, Claris et Laris et Melyador de Jean Froissart. À la suite d'une introduction faisant le point sur les nombreuses études consacrées aux noms propres dans les textes (pp. 9-39), le volume s'organise en trois parties.

2 La première partie («Matérialité du nom propre», pp. 41-182) concerne les modalités de repérage du nom propre dans les textes médiévaux. Elle aborde les questions codicologiques à se poser pour l'identification des noms dans les manuscrits et dans les éditions ainsi que les éléments linguistiques et les procédés stylistiques liés à la présence ou à l'absence du nom propre.

3 La deuxième partie («Imaginaires du nom propre», pp. 183-321) s'intéresse d'abord à l'univers de référence du nom propre, à ses héritages et influences, notamment en relation à la matière de Bretagne, mais aussi à la part d'innovation de chaque récit. Elle aborde également les effets que l'interprétation sémantique du nom peut avoir sur l'intrigue du roman et la réception des noms propres romanesques à la fin du Moyen Âge.

4 La troisième partie («L'ordenance des noms», pp. 323-462) examine le nom propre dans sa capacité d'organiser et de créer des lignes directrices dans le récit; les romans du corpus principal sont ainsi interrogés en relation aux liens de parenté et à la hiérarchie 
des êtres, mais aussi pour les passages dans lesquels le nom est un élément narratif décisif (reconnaissance ou méconnaissance du nom, quiproquo, dissimulation ou quête d'identité, invocation, constitution d'une renommée etc.).

5 La Bibliographie (pp. 477-500) sépare le corpus principal, le corpus secondaire et les études; elle s'accompagne d'un Index des noms de personnes, de personnages, d'ethnies, de nations et d'ordres (pp. 501-510) et d'un Index des noms de lieux (pp. 511-513) qui facilitent la consultation du volume. 